\title{
BARRAGEM SUBTERRÂNEA: TECNOLOGIA SUSTENTÁVEL DE CAPTAÇÃO, ARMAZENAMENTO DE ÁGUA E CONVÍVIO COM O SEMIÁRIDO
}

\author{
BARRAGEN UNDERGROUND: TECNOLOGÍA SOSTENIBLE PARA \\ RECOLECCION, ALMACENAMIENTO DE AGUA Y VIDA CON LA SEMIÁRIDAS
}

\author{
BARRAGEN UNDERGROUND: SUSTAINABLE TECHNOLOGY FOR \\ COLLECTION, STORAGE WATER AND LIVING WITH THE SEMI-ARID
}

\author{
Thiago Pereira de SOUSA ${ }^{1}$ \\ Eduardo Pereira de Sousa NETO \\ Luana Raposo de Sá SILVEIRA ${ }^{3}$ \\ Elias Francisco dos Santos FILHO \\ Patrício Borges MARACAJÁ ${ }^{5}$
}

\begin{abstract}
RESUMO: Barragem subterrânea é toda estrutura que objetiva barrar o fluxo subterrâneo de um aqüífero pré-existente ou criado concomitantemente à construção da barreira impermeável, tendo sua parede totalmente abaixo da superfície do aluvião, ficando a água armazenada no perfil do solo. As principais vantagens das barragens subterrâneas são: pequena perda de água por evaporação; não alagamento das terras que passam a ter o cultivo beneficiado pela elevação do lençol freático, aproveitando o processo natural de sub-irrigação em grande parte do ano; pequeno custo de construção e manutenção; não existem riscos de rompimento; menor impacto ambiental que as barragens superficiais, onde o sistema rapidamente se integra ao meio ambiente. A pesquisa foi dividida em duas etapas, sendo que na primeira foi realizado um diagnóstico baseado na metodologia do Diagnóstico Rural Participativo - DRP, utilizando as seguintes ferramentas: Observação participante, entrevista semi-estruturada, construção de mapas de recursos naturais da propriedade, construção de calendário de atividades (homens, mulheres e crianças), calendário sazonal, calendário de culturas e diário de campo (agricultores). A barragem subterrânea é uma alternativa tecnológica capaz de viabilizar a exploração agrícola e pecuária no semi-árido brasileiro, diminuindo os riscos da agricultura dependente de chuva, com aumentos significativos da produtividade das culturas.
\end{abstract}

Palavras-chave: Meio ambiente, aqüífero, evaporação.

\footnotetext{
${ }^{1}$ Mestrando pelo Programa de Pós-graduação em Fitotecnia da Universidade Federal Rural do Semi-Árido (UFERSA-PPGF), Mossoró, RN; tiagojd2009@ hotmail.com

${ }^{2}$ Graduando em Agronomia pela Universidade Federal de Campina Grande (UFCG-CCTA), Pombal, PB; gogaeduardo@hotmail.com

${ }^{3}$ Graduanda Ciências Agrárias pela Universidade Estadual da Paraíba (UEPB-CCHA), Catolé do Rocha, PB; luana.156@hotmail.com

${ }^{4}$ Graduando em Agronomia pela Universidade Federal de Campina Grande (UFCG-CCTA), Pombal, PB; gogaeduardo@hotmail.com

${ }^{5}$ Professor D. Sc. UAGRA/UFCG- Mestrando em Sistema Agroindustriais (UFCG), Pombal, PB, Brasil. patriciomaracaja@gmail.com
} 
RESUMEN: Presa de metro es toda estructura objetiva que se propaga el flujo subterráneo de un acuífero preexistente o creada al mismo tiempo que la construcción de la barrera impermeable, y su pared totalmente por debajo de la superficie del terreno aluvial, conseguir el agua almacenada en el perfil del suelo. Las principales ventajas de presas subterráneas son pequeña pérdida de agua por evaporación; no inundación de las tierras se benefició cultivando freático alto, disfrutando del proceso natural de sub-irrigación durante gran parte del año; pequeño costo de construcción y mantenimiento; no hay riesgo de rotura; menor impacto ambiental que las presas superficie, donde el sistema se integra rápidamente en el medio ambiente. La investigación se dividió en dos etapas, la primera es que el diagnóstico se realiza con base en la metodología de Diagnóstico Rural Participativo - PRA, con las siguientes herramientas: la observación participante, entrevistas semi-estructuradas, la construcción de mapas de recursos naturales de la propiedad, la construcción de calendario de actividades (hombres, mujeres y niños), calendario estacional, culturas y diario de campo (agricultores). La represa subterránea es una tecnología alternativa capaz de permitir la agricultura y la ganadería en la región semiárida brasileña, disminuyendo el riesgo de la agricultura dependiente de la lluvia, con aumentos significativos en los rendimientos de los cultivos.

Palabras clave: medio ambiente, los acuíferos, la evaporación.

ABSTRACT: Underground dam is any structure that aims to stop the underground flow of a pre-existing aquifer or created concurrently with the construction of impermeable barrier, with its wall entirely below the surface of the alluvium, getting the water stored in the soil profile. The main advantages of underground dams are small loss of water by evaporation; no flooding of the lands shall be benefited by cultivating higher water table, enjoying the natural process of sub-irrigation for much of the year; small cost of construction and maintenance; there is no risk of breakage; less environmental impact than surface dams, where the system quickly integrates into the environment. The research was divided into two stages, the first being that a diagnosis was made based on the methodology of Participatory Rural Appraisal PRA, using the following tools: participant observation, semi-structured interviews, building maps of natural resources of the property, building calendar of activities (men, women and children), seasonal calendar, cultures and field diary (farmers). The underground dam is an alternative technology capable of enabling the farming and ranching in the Brazilian semi-arid region, decreasing the risk of rain-dependent agriculture, with significant increases in crop yields.

Keywords: Environment, aquifer, evaporation.

\section{INTRODUÇÃO}

A tecnologia das barragens subterrâneas é bastante simples, sendo conhecida na bibliografia desde mais de 60 anos, essa tecnologia não requer elevado nível de formação para sua operação e manutenção. Entretanto, como qualquer outra tecnologia, o produtor necessita 
conhecer seu princípio de funcionamento para obter maior eficiência no uso do sistema (PORTO et al, 1995).

Barragem subterrânea é toda estrutura que objetiva barrar o fluxo subterrâneo de um aqüífero pré-existente ou criado concomitantemente à construção da barreira impermeável, tendo sua parede totalmente abaixo da superfície do aluvião, ficando a água armazenada no perfil do solo. Esses tipos de barragens são construídas principalmente na região nordeste do Brasil, com o objetivo de aumentar a disponibilidade de água no meio rural.

Cerca de $70 \%$ das propriedades rurais do Nordeste brasileiro são constituídas de pequenas áreas, com media de 100 hectares, o que impossibilita a construção de grandes barragens, desse modo que as atividades agropecuárias ficam limitadas em função da má distribuição das chuvas ao longo do ano (AZEVEDO, et al., 2010).

O risco da agricultura dependente de chuva e a falta de água para o consumo humano e para as criações constituem as principais causas da baixa qualidade de vida do meio rural da região nordeste Brasileiro, onde a produção e a produtividade agrícola são limitadas pela irregularidade na distribuição espaço-temporal da chuva, considerada mais grave do que sua escassez propriamente dita.

Dessa forma se enfatiza a necessidade de armazenar água, principalmente no subsolo, onde a barragem subterrânea constitui uma alternativa de captação e armazenamento de água para incrementar a produtividade agrícola e viabilizar a exploração de pequenas e médias propriedades rurais.

As principais vantagens das barragens subterrâneas são: pequena perda de água por evaporação; não alagamento das terras que passam a ter o cultivo beneficiado pela elevação do lençol freático, aproveitando o processo natural de sub-irrigação em grande parte do ano; pequeno custo de construção e manutenção; não existem riscos de rompimento; provoca menor impacto ambiental que as barragens superficiais, sendo que o sistema rapidamente se integra ao meio ambiente (LIMA, et al., 2013).

Objetivou-se com este trabalho, estudar a importância sócio-ambiental da barragem subterrânea no desenvolvimento e convívio sustentável com semi-árido brasileiro.

\section{MATERIAL E MÉTODOS}

O estudo foi realizado na propriedade rural "Fazenda Serrota", situada no Sítio Serrota, município de João Dias-RN, localizada no Alto Oeste Potiguar do Rio Grande do 
Norte (latitude $06^{\circ} 15^{\prime} 39,15^{\prime \prime} \mathrm{S}$ e longitude $37^{\circ} 48^{\prime} 41^{\prime \prime} \mathrm{W}$ ) com uma área total de 120 hectares, no período de Março a Novembro de 2013. O clima do município de acordo com a classificação de Koppen é do tipo BSWH, ou seja, seco e muito quente do tipo estepe, com estação chuvosa no verão e com temperatura do mês mais frio superior a $18^{\circ} \mathrm{C}$.

A pesquisa foi dividida em duas etapas, sendo que na primeira foi realizado um diagnóstico baseado na metodologia do Diagnóstico Rural Participativo - DRP, utilizando as seguintes ferramentas: Observação participante, entrevista semi-estruturada, construção de mapas de recursos naturais da propriedade, construção de calendário de atividades (homens, mulheres e crianças), calendário sazonal, calendário de culturas e diário de campo (agricultores).

A segunda etapa consistiu de uma avaliação dos indicadores ambientais, sociais e econômicos, pré-estabelecidos quando da realização do diagnóstico da primeira etapa, assim como nas observações (monitoramento do agroecossistema da barragem), realizado durante os oito meses de estudo.

Nas atividades com os agricultores foram utilizadas dinâmicas de grupo, buscando-se estimular a participação da família nas atividades e na construção coletiva das ferramentas propostas, chegando-se assim a uma visão mais ampla da propriedade e das percepções que cada indivíduo (mulher, homem, adolescente e crianças) tem de seu ambiente e das transformações que ocorreram e ocorrem a partir do momento que são implantadas as tecnologias apropriadas para a realidade do semiárido.

\section{RESULTADOS E DISCUSSÃO}

Pensada, inicialmente para oferecer uma alimentação mais adequada às famílias, em momentos de escassez, as barragens subterrâneas têm surpreendido pelo seu potencial de aproveitamento da água de chuva. Ela fornece água potável de qualidade para uso doméstico através de poço construído em sua área de armazenamento, fornece água para as criações e pequenos cultivos irrigados fora da bacia da barragem.

De acordo com Lima et al. (2013), na construção dessas barragens devem ser observados alguns fatores, tais como: a precipitação média da região, vazões dos rios, riachos ou linhas de drenagem, granulometria dos solos da área selecionada, qualidade da água, quanto ao aspecto salinidade, capacidade de armazenamento do aquífero e profundidade da camada impermeável. 
Segundo Azevedo et al. (2010), a barragem subterrânea consiste dos seguintes componentes: Área de captação - representada pela bacia hidráulica delimitada por divisor de água topográfico e freático; Área de plantio - é a própria bacia hidráulica. Entretanto, dependendo da disponibilidade de água, da profundidade e das características do solo, dentro dessa bacia, pode-se construir reservatório, poço amazonas, para armazenar o excedente de água da área de captação/plantio; Parede da barragem ou septo impermeável - compreende o barramento ou parede da barragem, também conhecida como septo impermeável, tem a função de interceptar o fluxo de água superficial e subterrâneo, dando origem à formação e/ou elevação do lençol freático. Esta parede pode ser construída por material compactado (solo argiloso, solo-cimento ou solo-bentonita, com coeficiente de permeabilidade de pelo menos $10^{-5} \mathrm{~cm} / \mathrm{s}$ ), alvenaria de pedra, diafragma com lona plástica ou concreto. Sangradouro possui a função de eliminar o excedente de água da área de captação/plantio. Esse dispositivo é necessário para permitir o controle do nível d’água na bacia de acumulação, a fim de assegurar aeração adequada às plantas no período de maior fluxo subterrâneo, e um sistema de captação que possibilite a utilização dos recursos hídricos armazenados e, em conseqüência, sua completa renovação no período das chuvas, evitando-se assim a acumulação de sais.

As famílias estudadas afirmam que mesmo a barragem subterrânea ser uma tecnologia de captação e armazenamento de água da chuva e ter proporcionado melhorias na propriedade, elas ainda sofrem, em menor proporção, com os períodos de seca. Ressaltam que a barragem proporcionou mudanças nos hábitos alimentares, permitindo uma maior diversificação de cultivos, e consequentemente uma maior variedade de alimentos disponíveis.

A diversificação de atividades, Ferreira et al. (2011), é uma estratégia (consciente ou inconsciente) que os agricultores familiares criaram para garantir a sua reprodução social, econômica, cultural e de práticas agrícolas, levando os homens e mulheres do campo a buscarem novas formas de gerar renda para a propriedade.

Segundo Silva et al. (2013), nas pequenas e médias propriedades, as áreas potencialmente agricultáveis são os baixios, e nestes, geralmente, são construídos os reservatórios de águas superficiais, cobrindo totalmente a área explorável. A implantação da barragem subterrânea elimina essa limitação, pois a área de armazenamento de água é a mesma de plantio, ou seja, de exploração agrícola (Figura 01). 


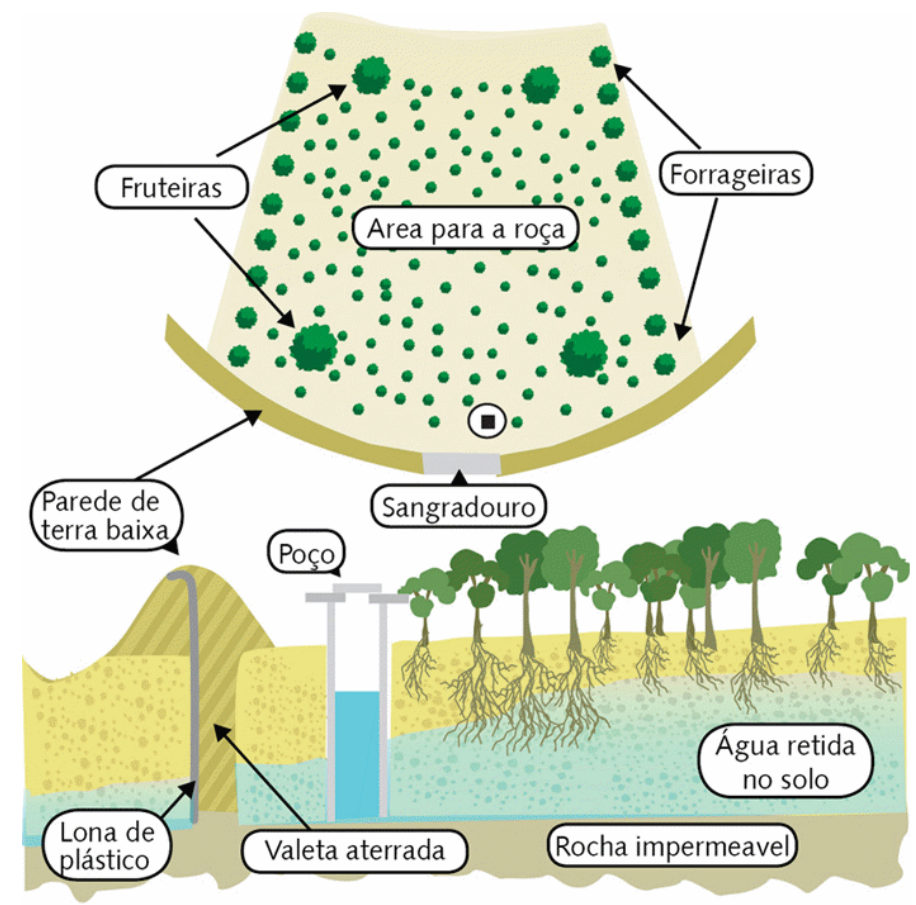

Figura 01: Desenho esquemático do funcionamento da barragem subterrânea. Adaptado. Fonte: FERREIRA et al., 2011.

De acordo com Santos et al. (2008), após a primeira chuva, a barragem estará em condições de ser usada para irrigação e/ou subirrigação, onde baseados em outros trabalhos, recomendam: $\mathbf{1}^{\mathbf{0}}$ - Utilização da faixa com culturas anuais (milho, feijão aipim, etc.) e/ou perenes, como fruticultura e capineira, haja visto que o solo estará mais úmido abaixo da superfície (variando conforme a topografia da área), onde as plantas retiram água para suas necessidades sem custos (de irrigação e/ou motobombeamento) para o produtor. $\mathbf{2}^{\mathbf{0}}$ Utilização do poço como opção para o produtor instalar sistema de bombeamento para irrigação e/ou subirrigação. $3^{\mathbf{o}}$ - Utilização da área mais saturada (na época das chuvas boa parte dessa área se transforma em espelho d'água) para cultivo de culturas que suportam maiores umidades em seu ciclo produtivo.

\section{CONCLUSÕES}

A barragem subterrânea é uma alternativa tecnológica capaz de viabilizar a exploração agrícola e pecuária no semi-árido brasileiro, diminuindo os riscos da agricultura dependente de chuva, com aumentos significativos da produtividade das culturas. 
Apesar de sua simplicidade, a barragem subterrânea requer alguns cuidados na construção, devendo-se observar principalmente a escavação da valeta, que deve ser até à camada impermeável e evitar problemas de salinização dos solos.

Os sistemas de produção baseados na agroecologia podem transformar as limitações do semiárido em potencialidades, partindo delas, para entender e promover uma convivência produtiva e sustentável.

A tecnologia de barragens subterrâneas pode ser utilizada com sucesso quando se faz estudos preliminares da qualidade da água dos recursos hídricos disponíveis na bacia hidrográfica, tipo, dimensão e espessura do material aluvial, que definirão a capacidade de armazenamento da barragem e permitirão a programação adequada de seu aproveitamento.

\section{REFERÊNCIAS BIBLIOGRAFICAS}

AZEVEDO, M. A.; NASCIMENTO, J. W. B.; FURTADO, D. A. Técnicas construtivas para barragens subterrâneas, bapucosa e poços amazonas. Revista Educação Agrícola Superior. Brasília, v.25, n.1, p.31-36, 2010.

FERREIRA, G. B.; COSTA, M. B. B.; SILVA, M. S. L.; MOREIRA, M. M.; GAVA, C. A. T.; CHAVES, V. C.; MENDONÇA, C. E. S. Sustentabilidade de agroecossistemas com barragens subterrâneas no semiárido brasileiro: a percepção dos agricultores na Paraíba. Revista Brasileira de Agroecologia, Cruz Alta, v.6, n.1, p.19-36, 2011.

LIMA, A. O.; DIAS, N. S.; NETO, M. F.; SANTOS, J. E. J.; REGO, P. R. A.; LIMA-FILHO, F. P. Barragens subterrâneas no semiárido Brasileiro: analise histórica e metodologias de construção. Irriga, Botucatu, v.18, n.2, p.200-211, 2013.

PORTO, E. R.; BRITO, L. T. L.; SILVA, A. S.; SILVA, D. A. Estudo de caso - barragem subterrânea. EMBRAPA-CPATSA. Petrolina, PE, 1995. 12p.

SANTOS, M. O.; FREITAS, I. M.; BRITTO, L. T. L.; ANJOS, J. B. Barragem subterrânea: água para uso na agropecuária. Manual Técnico, n.17. Niterói: Programa Rio Rural, 13f, 2008.

SILVA, M. S. L.; ARAÚJO, A. H. R. C.; FERREIRA, G. B.; CUNHA, T. J. F.; OLIVEIRA NETO, M. B. Barragem subterrânea: contribuindo para a segurança alimentar e nutricional das famílias do Semiárido brasileiro. In: VIII CONGRESSO BRASILEIRO DE AGROECOLOGIA, 2013, Porto Alegre. Anais... Cruz Alta: ABA-Agroecologia, 2013. P. 05 . 